\title{
BUILDING-INTEGRATED SOLAR SYSTEMS FOR INDEPENDENT ENERGY SUPPLY OF BUILDINGS
}

\author{
Dr Viktor Elistratov* \\ State Polytechnical University, St.Petersburg, Russia \\ Vladimir Petrov \\ State Polytechnical University, St.Petersburg, Russia \\ Dr Rifat Alihodžić \\ Faculty of Architecture, Podgorica, Montenegro
}

This article proposes to apply active building-integrated solar systems for independent energy supply of buildings, their classification is presented. The classification of building-integrated photovoltaic (BIPV) technologies is carried out. The international qualified standards of BIPV systems are presented. International market and economic aspects of BIPV systems implementation are analyzed in the article. The methodology of calculation of solar radiation income on variously oriented surfaces in real cloudiness conditions is given. The software, which was developed in order to calculate solar radiation income on differently orientated inclined surfaces in real weather conditions, is described. Also paper contains calculations of solar radiation income on variously orientated surfaces and recommendations for optimal disposition of photovoltaic modules and solar thermal collectors.

Key words: Building-integrated solar systems, BIPV systems, Energy-efficient buildings, Solar energy

\section{INTRODUCTION}

Construction of power-efficiency buildings is one of the actual tendencies of modern architecture. Implementation of active building-integrated solar systems for independent energy supply of buildings creates the necessary prerequisites for zero energy and zero emission buildings construction that will contribute the improvement of ecological situation in big cities and increase the energy efficiency of urban development [02, 03, 05, 22, 26]. Active building-integrated solar systems can be categorized into three groups:
- Photovoltaic (PV) systems

- Solar thermal systems

- Photovoltaic and thermal systems

Solar photovoltaic (PV) systems are one of the most promising renewable energy technologies for building application, producing electricity directly from solar radiation without harming the environment. Building integrated photovoltaic (BIPV) systems (Figure 1, left), where solar cells are integrated within the climate envelopes of buildings and utilizing solar radiation to produce electricity [15].

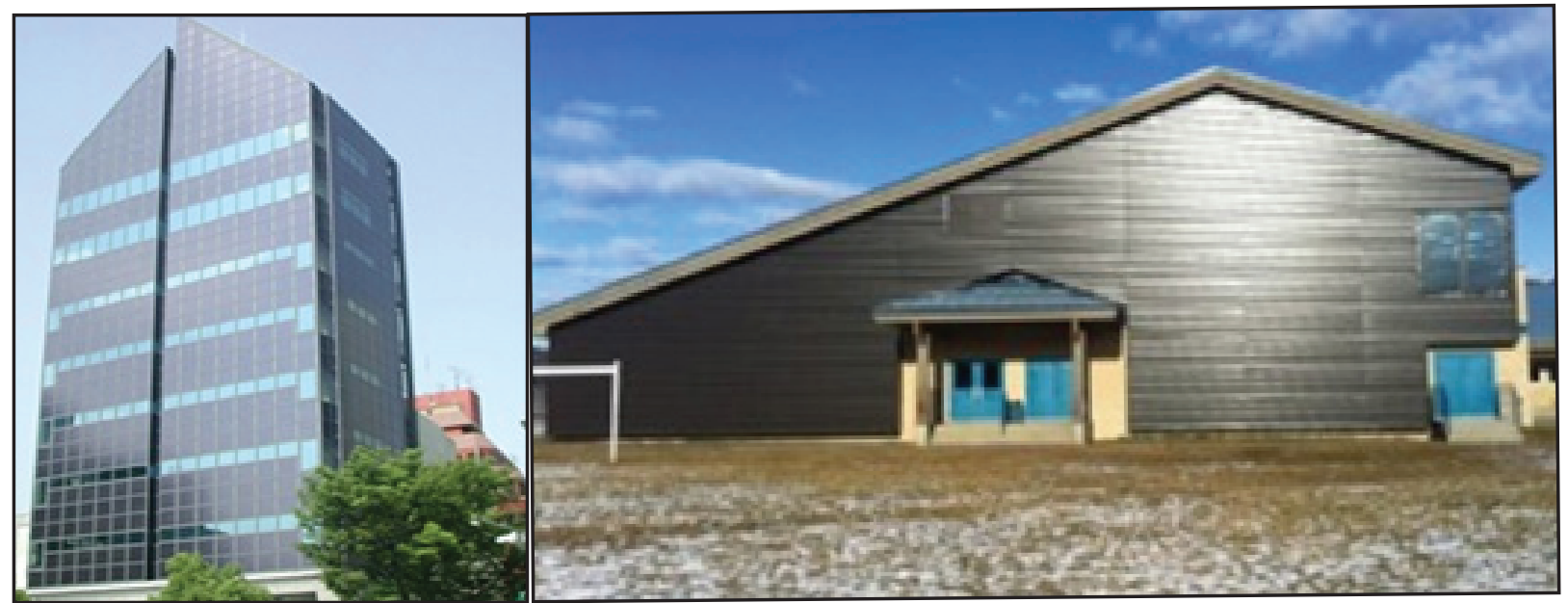

Figure 1: Examples of BIPV (left) and BIST (right) façades

*State Polytechnical University, Politekhnicheskayaul., 29,195251, Saint-Petersburg, Russia; 
Also it is possible to integrate solar thermal systems (BIST) into the buildings in order to transform solar energy into thermal (Figure 1, right).

One of last technologies in this sphere is building-integrated photovoltaic and thermal (BIPVT) systems, which supplies generation of electrical and thermal energy at the same time.

These competitive new technologies may represent a powerful and versatile tool for reaching main goals with respect to aesthetical, economical and technical solutions.

Moreover, article gives BIPV systems classification, considered international qualified standards of BIPV systems. The methodology of calculation of solar radiation income on variously oriented surfaces in real cloudiness conditions is given. Based on this methodology, was developed the software in order to calculate solar radiation income on differently orientated inclined surfaces in real weather conditions in point with inputted geographical coordinates. Paper contains calculations of solar radiation income on variously orientated surfaces. Recommendations for optimal disposition of PV modules and solar thermal collectors in climatic conditions of Saint-Petersburg are given.

\section{PV SYSTEMS CATEGORIZATION}

There are two main types of design decisions for PV systems disposition on building:

- Building-applied photovoltaic (BAPV) systems: placement and consolidation of PV modules over the building construction.
- BIPV systems: replacement parts of the building construction using integrated PV modules.

BAPV systems are maintained on the building after construction is complete, hence not directly related to the building structures aspects. Nevertheless, in the historical center of Saint-Petersburg, according to the regional legislation, disposition of facilities on frontal facades of historic buildings is practically forbidden. In this case, BIPV systems are one the most perspective solutions [01, 10, 21]. At the same time, for apartment block and for industrial buildings outside the city center there is a possibility to apply both technologies.

The range of BIPV products is very wide, and they may be categorized in several different ways.

The categorization mainly performed based on the product description. BIPV products can be divided into following groups [14]:

\section{- BIPV tile products \\ - BIPV foil products \\ - BIPV glazing products}

BIPV tile products may cover the entire roof or selected parts of the roof. This type of BIPV products looks like traditional roof tiles with the identical properties, but with the PV modules functions [19, 20]. BIPV roof tiles are suitable for easy roofs retrofitting. Example of BIPV tiles is presented on Figure 2.

BIPV foil products are lightweight and flexible, which leads to easy installation prevailing weight constraints. As a rule, BIPV foil products are made from thin-film cells to maintain the flexibility in the foil. Considering its characteristics, such

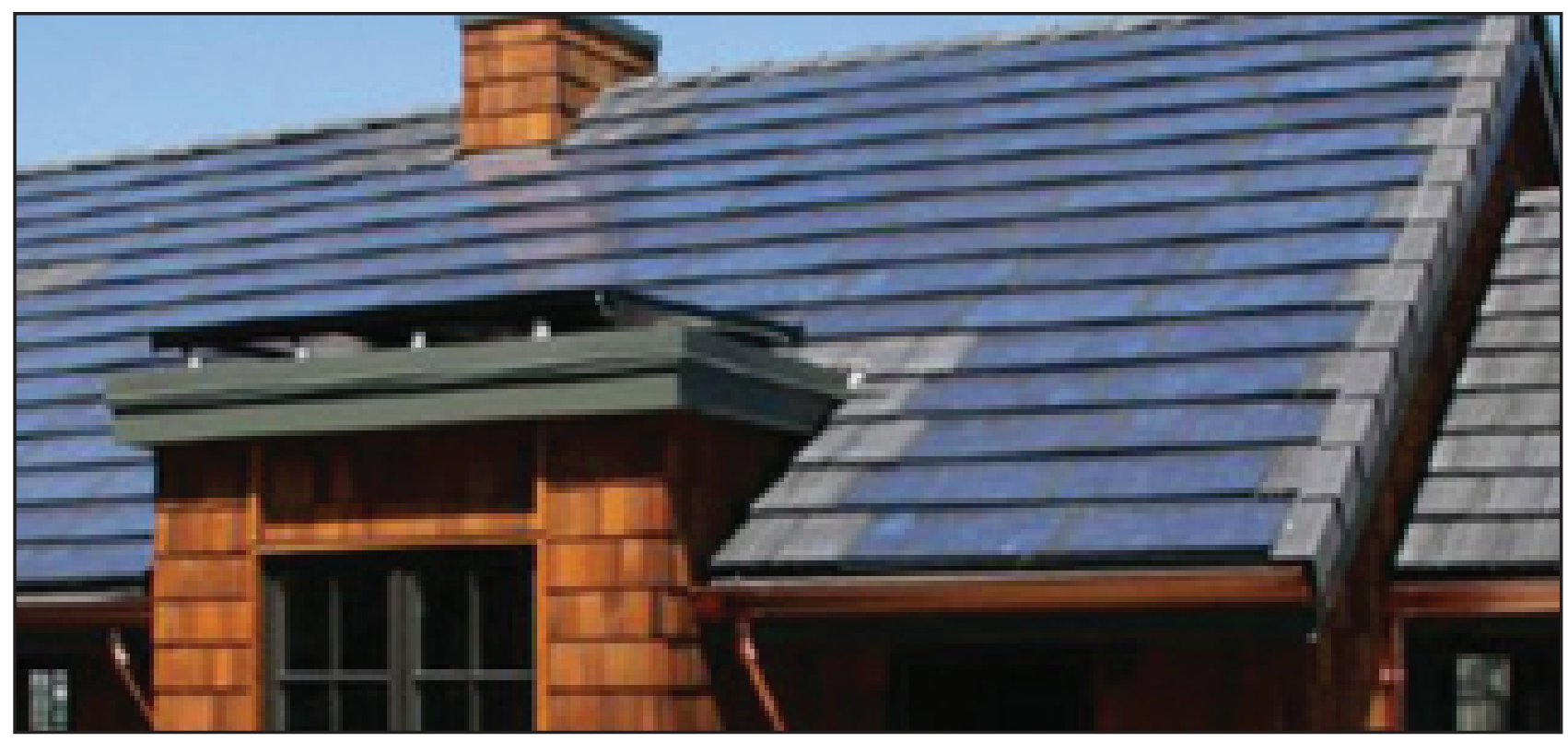

Figure 2: Example of BIPV tiles. 
as flexibility and lightweight, this kind of BIPV products can be maintained into practically any part of the building: roof, façade, etc.

BIPV glazing products provide a great diversity of options for windows, glassed or tiled façades and roofs (Figure 3 ).
The solar cells glazing modules transmit daylight and serve water and sun protections. The distance between the solar cells depends on needed transparency level and the criteria of electricity production.

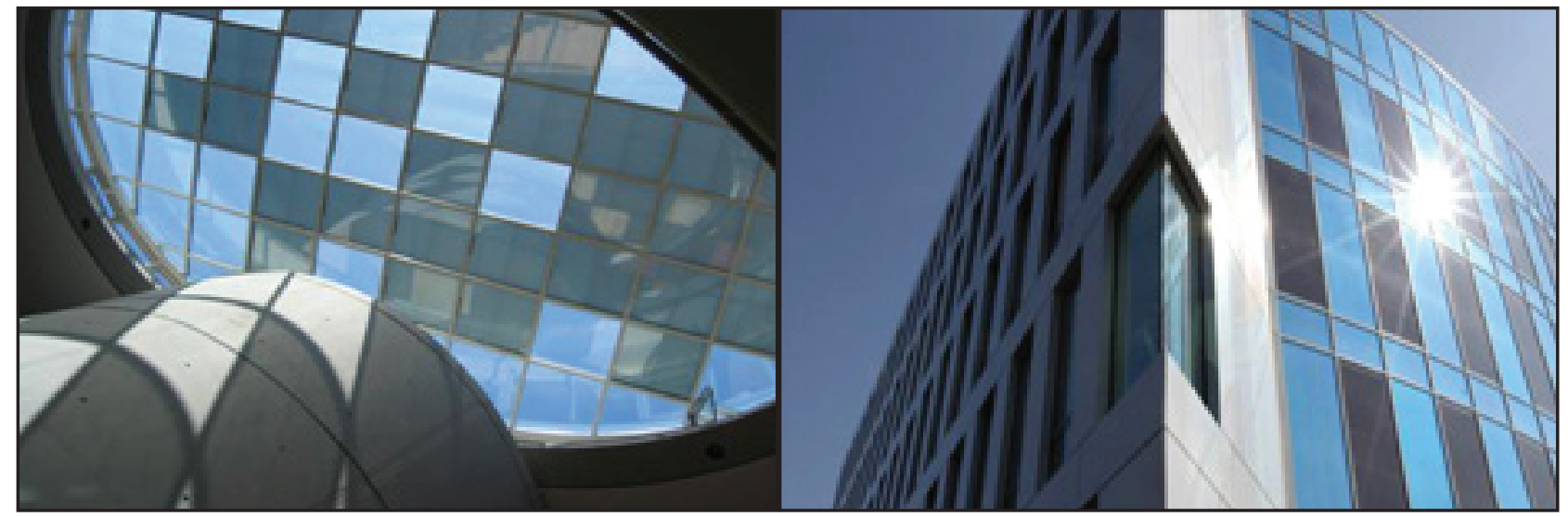

Figure 3: Examples of BIPV glazing products for roofs (left) façade (right)

\section{REQUIREMENTS AND STANDARDS FOR BIPV SYSTEMS}

BIPV systems are considered as a functional part of the building structure or they are architecturally integrated into the building design, thus serving simultaneously as both a building envelope material and a power source generating electricity. I.e., the BIPV system must fulfil the requirements of both the building envelope material and construction, and the PV solar cells. Such characteristics of BIPV system as mechanical properties, durability versus climatic exposure conditions, rain and wind tightness, various building physical issues (e.g. heat and moisture transport in the building envelope) have to be considered and accounted for [16, 17, 18].

BIPV systems must obey specific standards in force in the country of use, most important of them are: EN 61646 "Thin-film terrestrial photovoltaic (PV) modules - design qualification and type approval" (equal to IEC 61646) [07], EN 61215 "Crystalline silicon terrestrial photovoltaic (PV) modules - Design qualification and type approval" (equal to IEC 61215) [06], EN 61730-1 "Photovoltaic (PV) module safety qualification - Part 1: Requirements for construction" [08], EN 61730-2 "Photovoltaic (PV) module safety qualification - Part 2: Requirements for testing" [09] and UL 1703 "UL standard for safety flatplate photovoltaic modules and panels". Thus currently existing European standards does not completely regulate requirements for BIPV sys- tems in terms of Building standards (ISO, CEN), development of new standards and methods of testing BIPV systems is essential.

\section{ECONOMIC ASPECTS OF BIPV SYSTEMS}

The global market for BIPVs grown to $\$ 1.8 \cdot 109$ in 2009 and expected to grow to $\$ 8.7 \cdot 109$ in 2016 (according to consulting firm NanoMarkets, New York). As PV panels occupy a large area for installation, the associated financial challenge could be best answered by space-saving technologies like BIPV systems. Incorporation of PV materials into products such as roofing materials, windows and glassed facades provides the opportunity for cost reduction by replacing common building materials with PV materials at marginal costs [24, 25]. In comparison to steel, aluminum, glass or other more conventional cladding materials, installing BIPV systems adds only a marginal extra cost $(2-5 \%)$ to the overall construction costs of a commercial building. For a building owner, the installation and operation cost of the BIPV system might be offset by selling the surplus electricity to a utility company. Over time, the cost of a PV system will decline with the improvement of technical advances, resulting into a lower price per kW installed [15], which is an important part of the development aimed at making installation and building integration of PV products profitable without subsidies [28-33]. 


\section{METHODOLOGY OF SOLAR RADIATION INCOME ESTIMATION IN REAL WEATHER CONDITIONS}

In the task of solar and thermal technologies efficiency definition it's necessary to know electrical or thermal generation value, which depends on solar radiation income in real weather conditions. That is why, for right efficiency definition and appropriation of their installation firstly should be defined solar radiation income on the inclined surface, value of this irradiance depends on inclination angle and orientation.

To define solar radiation density on horizontal surface considering atmosphere losses (absorption and scattering) was applied parametrical model «lqbal model $C »[13]$. In this model direct normal irradiance on horizontal surface $\left(\mathrm{W} / \mathrm{m}^{2}\right)$ can be calculated by the formula (1),

$E_{\text {hor }}^{\text {beam }}=0,9751 \cdot E_{C} \cdot A(n) \cdot \tau_{r} \cdot \tau_{o z} \cdot \tau_{\text {gas }} \cdot \tau_{w} \cdot \tau_{a} \cdot \cos \Theta_{z}$

where the factor 0.9751 is included because the spectral interval considered is $0.3-3 \mu \mathrm{m}$; EC is the solar constant which can be taken as $1367 \mathrm{~W} / \mathrm{m} 2$; $A(n)$ (dimensionless) is the eccentricity correction-factor of the Earth's orbit, depends on the day number of the year; $\tau_{\mathrm{r}}, \tau_{\mathrm{oz}}, \tau_{\mathrm{a}}, \tau_{\mathrm{gas}}, \tau_{\mathrm{w}}$ (dimensionless)are the Rayleigh, ozone, aerosols, gas and water scattering-transmittances respectively; $\Theta_{z}$ - incidence angle on the horizontal surface. The horizontal diffuse irradiance $E_{\text {hor }}^{\text {diff }}$ $\left(\mathrm{W} / \mathrm{m}^{2}\right)(2)$ is a sum of three components corresponding to the Rayleigh scattering after the first pass through the atmosphere, $\operatorname{Dr}\left(\mathrm{W} / \mathrm{m}^{2}\right)$; the aerosolsscattering after the first pass through the atmosphere, $\mathrm{Da}\left(\mathrm{W} / \mathrm{m}^{2}\right)$; and the multiple-reflection between the ground and sky, $\mathrm{Dm}\left(\mathrm{W} / \mathrm{m}^{2}\right)$ :

$E_{\text {hor }}^{\text {diff }}=D_{r}+D_{a}+D_{n}$

Finally, density of global solar irradiance $E_{h o r}^{g l o b}$ $\left(\mathrm{W} / \mathrm{m}^{2}\right)$ can be calculated by the formula (3):

$E_{\text {hor }}^{\text {glob }}=E_{\text {hor }}^{\text {beam }}+E_{\text {hor }}^{\text {diff }}=\frac{\left(E_{\text {hor }}^{\text {beam }}+D_{r}+D_{a}\right)}{1-\rho_{g} \cdot \rho_{a}}$

where $\rho_{a}$ (dimensionless) - the albedo of the cloudless sky; ; $\rho_{\mathrm{g}}$ (dimensionless) the ground albedo.

Additional information about model applied may be found in the studies [11, 28].

Adoption to the real cloudiness conditions in the hour density of solar radiation calculation accomplished in condition that daily average irradiance income in clean sky conditions approximate daily average irradiance income in real weather conditions (4) [04].

where $E_{\text {hor }}^{b_{\text {clear }}}, E_{\text {hor }}^{d_{\text {cher }}}$ and $E_{\text {hor }}^{b_{\text {real }}}, E_{\text {hor }}^{d_{\text {deat }}}\left(\mathrm{kWh} / \mathrm{m}^{2}\right)-$ minute values of direct and diffuse solar radiation densitv in clear skv and in real cloudiness conditions; $W_{\text {hor }}^{b}, W_{\text {hor }_{j}}^{d}$ and $W_{\text {hor }}^{b_{\text {cal }}}, W_{\text {hor }}^{d_{\text {cal }}}\left(\mathrm{kWh} / \mathrm{m}^{2}\right)-$ measured and calculated value of direct and diffuse radiation income on horizontal surface;

$E_{\text {hor }_{i}}^{b_{\text {real }}}=E_{\text {hor }_{i}}^{b_{\text {clear }}} \cdot \frac{W_{\text {hor }_{j}}^{b}}{W_{\text {hor }}^{b_{\text {call }}}} ; E_{\text {hor }_{i}}^{d_{\text {real }}}=E_{\text {hor }_{i}}^{d_{\text {clear }}} \cdot \frac{W_{\text {hor }_{j}}^{d}}{W_{\text {hor }}^{d_{\text {calc }}}}(4)$

j - day number of the year.

Calculation of solar irradiance income on the surface considering their orientation:

- Direct solar irradiance is calculated by the formula (5),

where $\Theta_{i}$ - incidence angle on the oriented surface.

Cosine of this angle can be defined by the formula (6). where $\beta$ - inclination angle of surface; $\gamma$ - the sun azimuth angle; $\omega_{\mathrm{C}^{-}}$- hour angle.

For instance, for differently oriented, vertically inclined surfaces $\left(\beta=90^{\circ}\right)$, cosines of incidence angle are given by the formulas for:

- South orientation, $\gamma=0^{\circ}(7)$;

- South-West orientation, $\gamma=45^{\circ}(8)$;

- West orientation, $\gamma=90^{\circ}(9)$;

- North-West orientation, $\gamma=135^{\circ}$ (10);

- North orientation, $\gamma=180^{\circ}(11)$;

- Diffuse solar irradiance is calculated by the formula (12).

If inclination angle differs from $0^{\circ}$, then on surface there is also the reflected from the Earth part of global solar irradiance.

Income of reflected solar radiation on inclined surface mainly depends on ground albedo and inclination angle of the surface itself $(\beta)$ and defined by the formula (13). Finally, density of global solar irradiance on differently orientated surfaces $E_{\text {oriented }}^{g_{\text {real }}}\left(\mathrm{kWh} / \mathrm{m}^{2}\right)$ defined by formula (14). 


$$
\begin{aligned}
& E_{\text {oriented }}^{b_{\text {real }}}=E_{\text {hor }}^{b_{\text {real }}} \cdot \frac{\cos \Theta_{i}}{\cos \Theta_{z}} \\
& E_{\text {oriented }}^{b_{\text {real }}}=E_{\text {hor }}^{b_{\text {real }}} \cdot \frac{\cos \Theta_{i}}{\cos \Theta_{z}}
\end{aligned}
$$

$$
\begin{gathered}
\cos \Theta_{v e r}^{s-w}=-\sin \delta_{n} \cdot \cos \varphi_{M} \cdot \cos 45^{\circ}+\cos \delta_{n} \cdot \sin \varphi_{M} \cdot \cos 45^{\circ} \cdot \cos \omega_{C}+ \\
+\cos \delta_{n} \cdot \sin 45^{\circ} \cdot \sin \omega_{C} \\
\cos \Theta_{v e r}^{s}=- \\
\sin \delta_{n} \cdot \cos \varphi_{M}+\cos \delta_{n} \cdot \sin \varphi_{M} \cdot \cos \omega_{C} \\
\cos \Theta_{v e r}^{w}=\cos \delta_{n} \cdot \sin \omega_{C}
\end{gathered}
$$

$$
\begin{gathered}
\cos \Theta_{v e r}^{n-w}=-\sin \delta_{n} \cdot \cos \varphi_{M} \cdot \cos 135^{\circ}+\cos \delta_{n} \cdot \sin \varphi_{M} \cdot \cos 135^{\circ} \cdot \cos \omega_{C}+ \\
+\cos \delta_{n} \cdot \sin 135^{\circ} \cdot \sin \omega_{C}
\end{gathered}
$$

$$
\cos \Theta_{i}=\sin \delta_{n} \cdot \cos \varphi_{M}-\cos \delta_{n} \cdot \sin \varphi_{M} \cdot \cos \omega_{C}
$$

$$
E_{\text {oriented }}^{d_{\text {real }}}=E_{\text {hor }}^{d_{\text {real }}} \cdot \frac{1+\cos \beta}{2}
$$

$$
E_{\text {oriented }}^{d_{\text {real }}}=E_{\text {hor }}^{d_{\text {real }}} \cdot \frac{1+\cos \beta}{2}
$$

$$
E_{\text {oriented }}^{g_{\text {real }}}=E_{\text {oriented }}^{b_{\text {real }}}+E_{\text {oriented }}^{d_{\text {real }}}+E_{\text {reflected }}^{\text {real }}
$$

\section{SOFTWARE}

Based on the presented in part 5 algorithm of solar radiation calculation income on inclined oriented surface was developed the software. This software gives a possibility to calculate daily, monthly and annual income of global solar irradiance on differently orientated inclined surfaces in point with inputted geographical coordinates (longitude, latitude) considering atmosphere losses in real cloudiness conditions.
Program initial data, entered by user, is: latitude and longitude of the region, calculation period (day numbers), inclination and azimuth angles, ground albedo value and factors necessary for atmosphere characteristics determination.Program main window and block diagram are shown on Figure 4 and Figure 5 respectively.

Output data, which consists of daily, monthly and annual income solar radiation density values, is recorded into the text file.

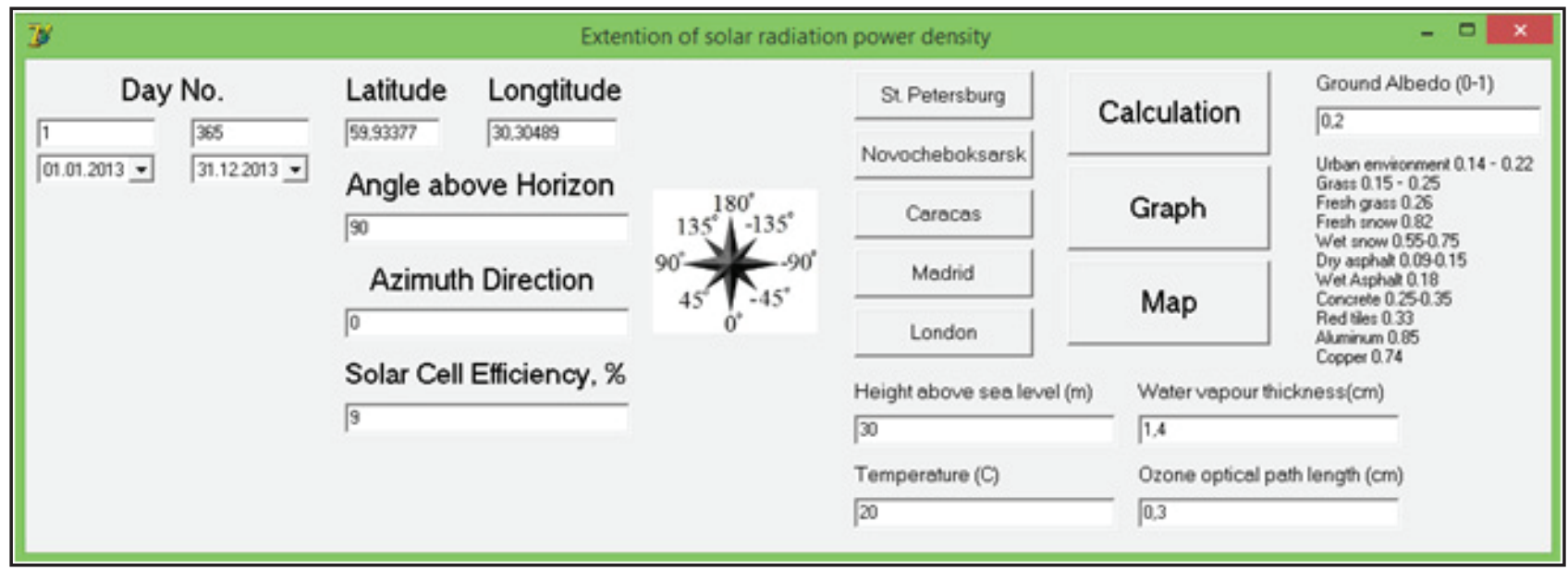

Figure 4: Program main window 


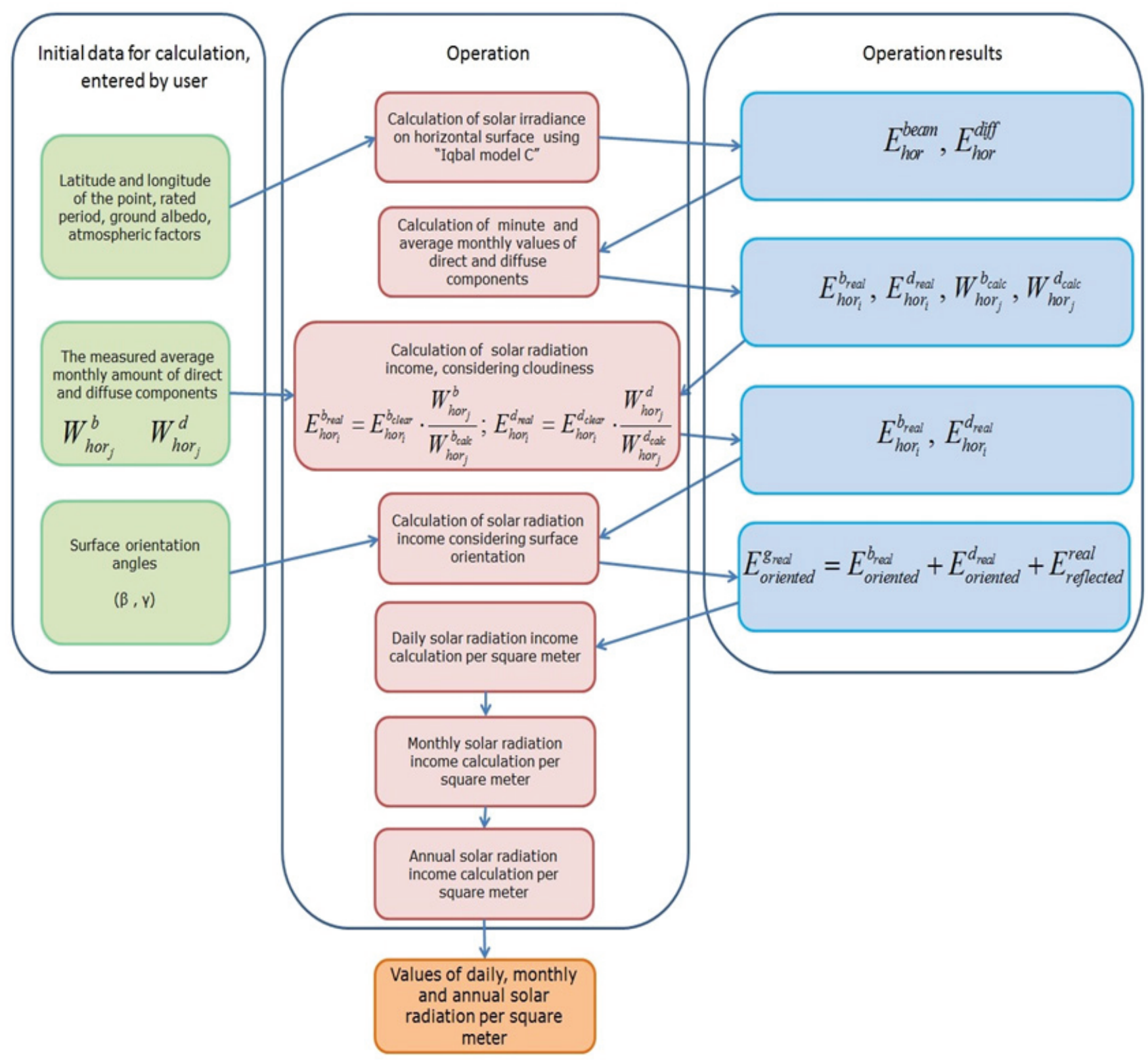

Figure 5: Block diagram.

\section{RESULTS}

By means of developed software was calculated annual solar radiance income in the climatic conditions of Saint-Petersburg for the most popular variants of solar systems integration into the buildings:

- Façade integration- vertical disposition of active solar surface

- Roof integration- inclination angle of surface is the same as the roof has - from 0 to 60 degree

\section{Calculation for vertical surface}

In case of vertical inclination, the most important parameter, which defines the efficiency of integrated solar system, is orientation. That is why for making optimal design decision in choosing orientation for photosensitive surfaces installation, comparative analysis of calculated solar irradiance data per square meter with different orientation was conducted.

Results are presented in Table 1 and on Figure 6. As it is evident from the Table 1, most efficient is south orientation, that was predictable. However choosingSouth-West (South-East) orientation, annual solar irradiance income decreased 
just by $6,36 \%$. Also, as it is evident from figure 6 , from May to July South-West orientation is the most efficient.

\section{Calculation for inclined surface}

Taking decision about value of orientation and inclination angle of the roof made with implementation of power-supply integrated systems, it is necessary to take in to consideration density of solar irradiance power flow per square me- ter of oriented surface. From previous results it is known that South orientation is the most efficient. In this case calculations in order to find optimal angle conducted in the assumption of South orientation.

Results are presented on Figure 7, which describes year solar irradiance income on South-oriented surface in real cloudiness conditions and without cloudiness depending on the inclination angle.

Table 1: Annual solar radiation income on vertically inclined differently oriented surfaces.

\begin{tabular}{|c|c|}
\hline Surface orientation & Annual solar radiation density, kWh/m2 \\
\hline South & 762,41 \\
\hline South-West (South-East) & 713,94 \\
\hline West (East) & 536,71 \\
\hline North-West (North East) & 312,02 \\
\hline North & 193,91 \\
\hline
\end{tabular}

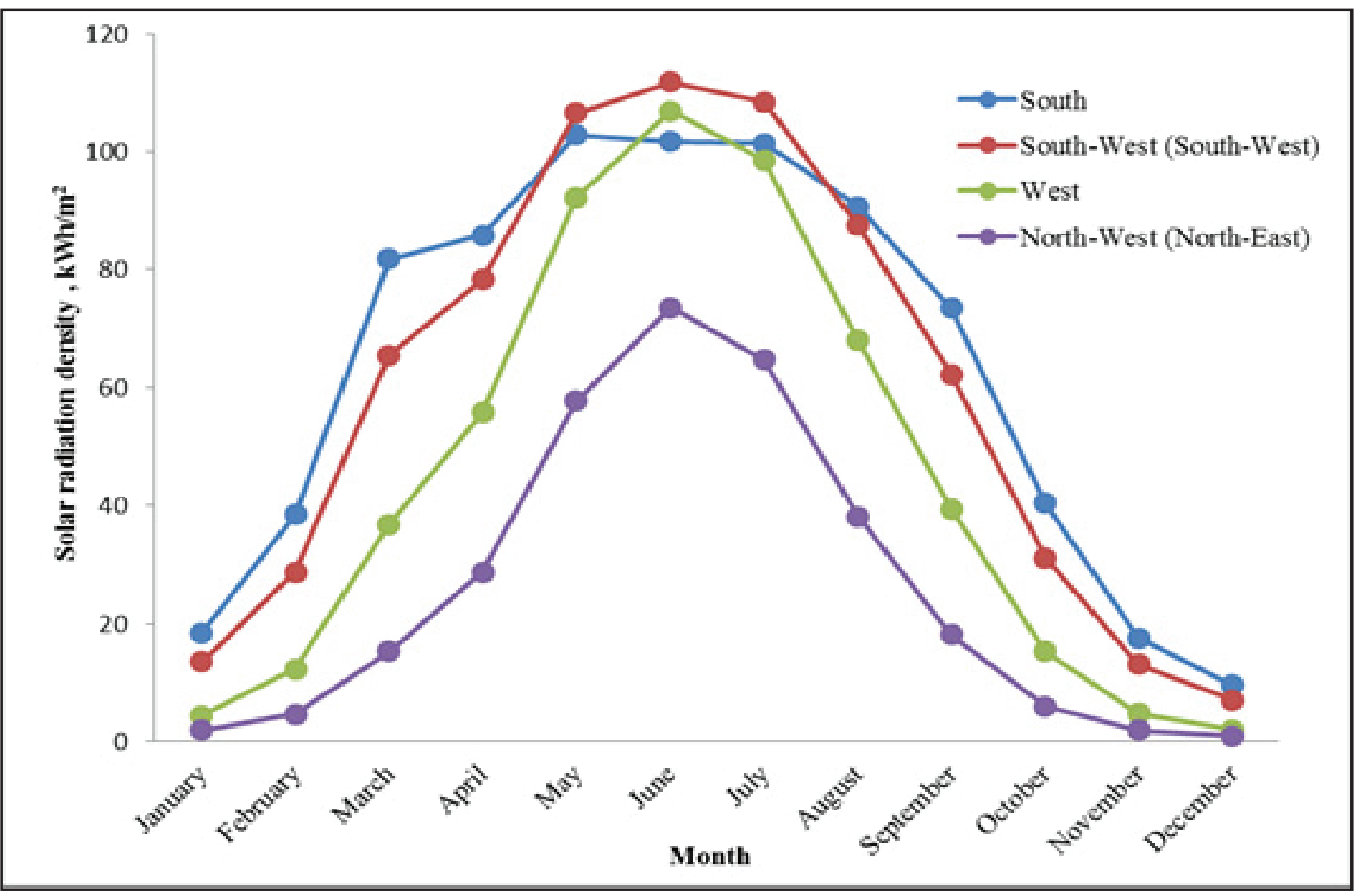

Figure 6: Monthly distribution of vertically inclined PV module power generation density. 


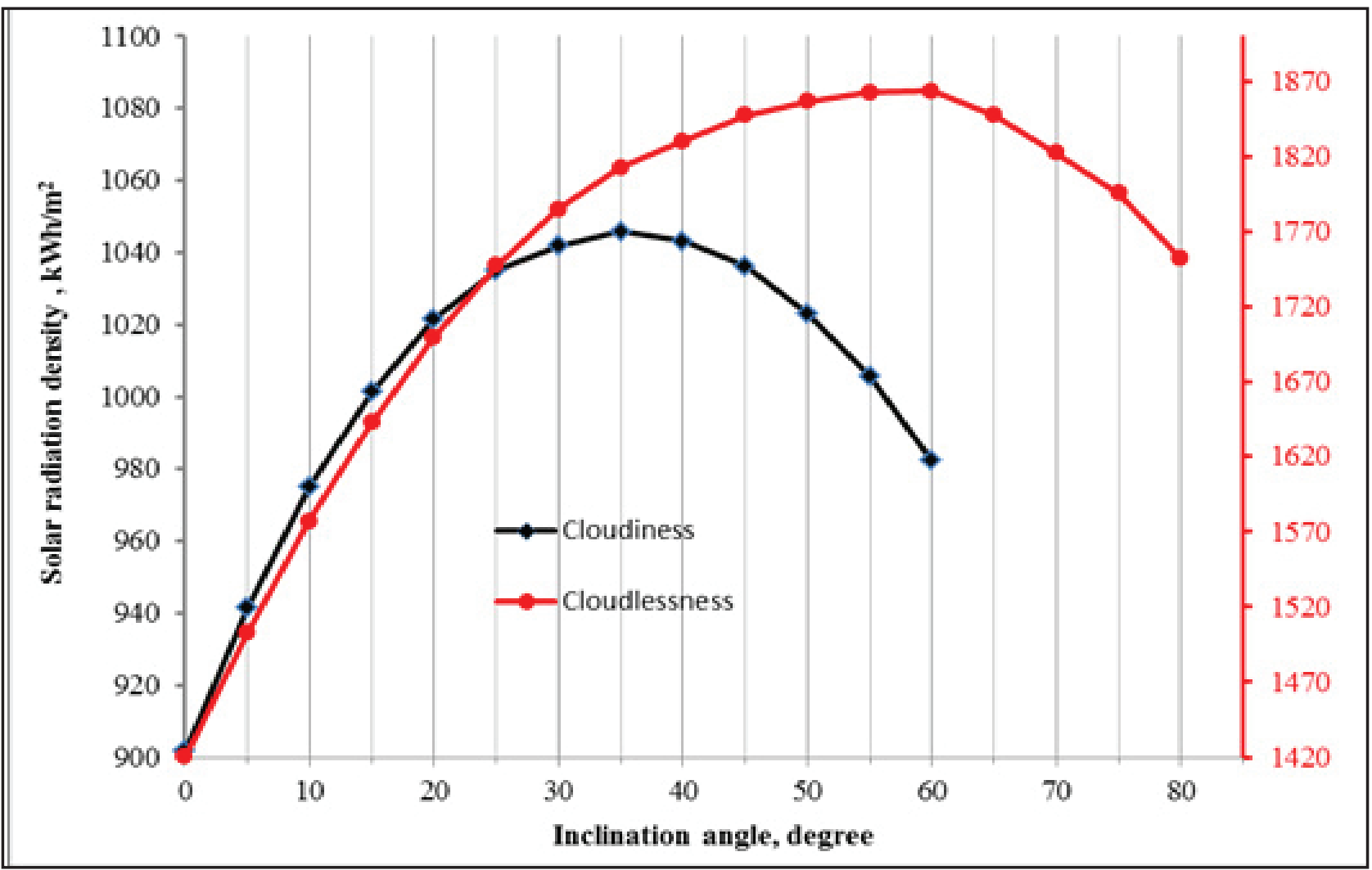

Figure 7: Annual solar radiation income density on differently inclined south oriented surface

The graph on Figure 7 shows that for calculation in cloudlessness conditions the most efficient angles are from 55 to 60 degrees. These results correspond with standard recommendations for selection optimal inclination angle, equal to the latitude of the area. For calculations considering cloudiness, optimal inclination angles are from 30 to 40 degrees. Maximum annual income of solar irradiance is about $1045,83 \mathrm{kWh} / \mathrm{m} 2$. However choosing angles from 15 to 55 degrees losses make up no more than $5 \%$.

\section{CONCLUSION}

1) Proposed to use building-integrated solar systems for independent power-supply of buildings.

2) The methodology of calculation of solar radiation income on variously oriented surfaces in real cloudiness conditions is presented.

3) Developed the software in order to calculate solar radiation income on differently orientated inclined surfaces in real weather conditions in point with inputted geographical coordinates considering atmosphere losses. Calculations performed by this program play an important role in taking design decision about building-integrated solar systems disposition on façade or roof of the building.

4) Optimal orientation of PV or solar thermal panels, integrated into vertical facadeson South, however in case of South-East (South-West) orientation losses are marginal $(6,36 \%)$. Maximum annual solar irradiance income in weather conditions of Saint-Petersburg, $762,41 \mathrm{kWh} / \mathrm{m} 2$, can be reached with South orientation.

5) For active integrated solar systems usage optimal roof inclination angle is from 30 to 40 degrees, not 60 degrees (the latitude of the area), because of the cloudiness.

6) Maximum annual income of solar irradiance in the weather conditions of Saint-Petersburg is about $1045,83 \mathrm{kWh} / \mathrm{m} 2$, it can be reached in case of South orientation. 


\section{REFERENCES}

1) Alihodzic, R., Murgul, V., Vatin, N., Aronova, E., Nikolić, V., Tanić, M., Stanković, D. (2014): Renewable Energy Sources used to Supply Pre-school Facilities with Energy in Different Weather Conditions. Applied Mechanics and Materials.Vol. 624.pp. 604-612

2) Aronova, E., Radovic, G., Murgul, V., Vatin, N. (2014): Solar Power Opportunities in Northern Cities (Case Study of Saint-Petersburg). Applied Mechanics and Materials. Vols. 587-589, pp. 348-354

3) Aronova, E., Murgul, V. (2013): The evaluation of the appropriateness for using solar energy technologies in the historical building of Saint-Petersburg and the climatic conditions of the North-West region, Architecture and Modern Information Technologies, № 2 (23), pp. 97-117.

4) Cvetkovska, M., Knezevic, M., Rogac, M. (2012): Thermal insulation effects on energy efficiency of building structures, Civil and Environmental Engineering UGM, Vol. 5, No. XXI/2, pp. 1209-1215.

5) Elistratov, V. (2013) Renewable energy, Saint-Petersburg: "Science".

6) Elistratov, V., Aronova E. (2012)Solar power plants. Estimation of the amount of solar radiation, Saint-Petersburg: Saint-Petersburg State Polytechnical University.

7) Elistratov, V., Knezevic, M., Denisov, R., Konishchev, M. (2014): Problems of constructing wind-diesel power plants in harsh climatic conditions, Journal of Applied Engineering Science, Vol. 12, № 1, pp 29-36

8) European Comitee for ElectrotechnicalStandarization, Crystalline Silicon Terrestrial Photovoltaic (PV) Modules - Design Qualification and Type Approval, EN 61215, European Standard, 2005.

9) European Commitee for ElectrotechnicalStandarization, Thin-film Terrestrial Photovoltaic (PV) Modules - Design Qualification and Type Approval, EN 61646, European Standard, 2008.

10) European Committee for ElectrotechnicalStandarization, Photovoltaic (PV) Module Safety Qualification - Part 1: Requirements for Construction, EN 61730-1, European Standard, 2007.
11) European Committee for ElectrotechnicalStandarization, Photovoltaic (PV) Module Safety Qualification - Part 2: Requirements for Testing, EN 61730-2, European Standard, 2007.

12) Golovina, S., Murgul, V. (2013): Sistemysolnechnogoenergosnabzheniya $v$ arkhitekture istoricheskikhgorodov, Vestnikgrazhdanskikh inzhenerov, № 5 (40), pp. 26-32.

13) Gueymard, C., (1993): Critical analysis and performance assessment of clear-sky solar-irradiance models using theoretical and measured data, Solar Energy, № 51(2), pp. 121-138.

14) IEA-PVPS, Grid connected power systems: Summary of IEA/PVPS Task $V$ activities from 1993 to 1998, T5-03, 1999.

15) qbal, M. (1983): An introduction to solar radiation. New-YorkAcademic press, № 6, pp. 101-119.

16) Jelle, B. P., Breivik, C. (2012): State-of-theart Building Integrated Photovoltaics, Energy Procedia, № 20, pp. 68-77.

17) Jelle, B. P., Breivik, C. (2012): The Path to the Building Integrated Photovoltaics of Tomorrow, Energy Procedia, №20, pp. 78-87.

18) Jelle, B.P., Breivik, C., Røkenes, H.D. (2012): Building integrated photovoltaic products: $A$ state-of-the-art review and future research opportunities, Solar Energy Materials and Solar Cells, № 10, pp. 69-96.

19) Lazarevska, M., Milanovic, M., Knezevic, M., Cvetkovska, M., Trombeva-Gavriloska, A., Samardzioska, T.(2014): An artificial neural network prediction model for fire resistance of composite columns, Journal of Applied Engineering Science, Vol. 12, № 1, pp 63-68

20) Lazarevska, M., Trombeva-Gavriloska, A., Knezevic, M., Samardzioska, T., Cvetkovska, M. (2012): Neural network prognostic model for RC beams strengthened with CFRP strips, Journal of Applied Engineering Science, Vol. 10,№ 1, pp. 27-30

21) Murgul, V. (2014): Features of energy efficient upgrade of historic buildings (illustrated with the example of Saint-Petersburg),Journal of Applied Engineering Science, Vol. 12 (1), pp 1-10

22) Murgul, V.:Solar energy systems in the reconstruction of heritage historical buildings of the northern towns (for example SanktPetersburg).Journal of Applied Engineering Science, Vol. 12 (2) (2014), pp 121-128 
23) Murgul, V. (2013): Capabilities of using the solar energy for energy supply of the dwelling buildings of the historical area of SaintPetersburg and for city environment quality improvement, Architecture and Modern Information Technologies, № 1 (22), pp. 1-18.

24) Murgul, V. (2013): Solar energy in the reconstruction of urban environment of historic building Saint-Petersburg, Architecture and Modern Information Technologies, № 2 (23), pp. 1-24.

25) Murgul, V. (2012): Improvement of the energy efficient properties of the houses in the historical area of Saint-Petersburg, Architecton: Proceedings of Higher Education, 4 (40), pp. 54-622

26) Nemova, D., Murgul, V., Golik, A., Chizhov, E., Pukhkal, V., Vatin N.(2014): Reconstruction of administrative buildings of the 70s: the possibility of energy modernization, Journal of Applied Engineering Science, Vol. 12 (1), pp 37-44

27) Norton, B., Eames, P.C., Mallick, T.K., Huang, M.J., McCormack, S.J., Mondol, J.D., Yohanis,Y.G., (2011): Enhancing the performance of building integrated photovoltaics, Solar Energy, № 85, pp. 1629-1664.

28) Paul, D., Mandal, S.N., Mukherjee, D., Bhadra-Chaudhuri, S.R. (2010): Optimization of significant insolation distribution parameters - A new approach towards BIPV system design, Renewable Energy,№ 35, pp. 2182-2191.
29) Pavlicic, N., Perazic, M., Djuric-Jocic, D., Knezevic, M. (2014): Engineering education in the field of civil engineering, Journal of Applied Engineering Science, Vol. 12, № 1, pp 11-18

30) Radovic, G., Murgul, V., Vatin, N.(2014): Fast urban development of Cetinje - old royal capital of Montenegro. Applied Mechanics and Materials. Vols. 584-586, pp. 564-569

31) Stanojević, D., Spasojević, V., Stevanović, I., Nedić, A. (2013): The contemporary automatic gearboxes - Review of the current state and interpretation of advantages and disadvantages of their use with respect to vehicle performance and traffic safety, Journal of Applied Engineering Science, 11 (2), pp. 89-97.

32) Wong L.T., Chow W.K. (2001): Solar radiation model, Applied Energy, № 69 (3), pp. 191-224.

33) Vuksanovic, D., Murgul V.,Vatin, N., Aronova E. (2014): Shadowing impact on amount of power generated by photovoltaic modules. Applied Mechanics and Materials. Vols. 587589, pp. 342-347

Paper sent to revision: 08.05.2014.

Paper ready for publication: 09.09.2014. 